• 研究报告・

\title{
重度砍伐后极小种群野生植物崖柏群落结构动态
}

\author{
赵志霞 1,2 赵常明 ${ }^{2}$ 邓舒雨 ${ }^{2,3}$ 申国珍 2,3 谢宗强 2,3 熊高明 ${ }^{*}$ 李俊清 ${ }^{*}$ \\ 1 (北京林业大学森林资源生态系统过程北京市重点实验室, 北京 100083) \\ 2 (中国科学院植物研究所植被与环境变化国家重点实验室, 北京 100093) \\ 3 (中国科学院大学, 北京 100049)
}

摘要: 砍伐导致濒危植物种群个体数量减少, 群落结构改变, 加剧物种灭绝风险。崖柏(Thuja sutchuenensis)为典型 极小种群野生植物, 森林砍伐是导致其种群数量急剧下降的主要原因。但是, 到目前为止, 有关崖柏种群及其群落 对砍伐的响应鲜有报道。本研究以重度砍伐后的崖柏群落为研究对象, 基于对崖柏群落固定样地的调查和两次复 查, 对比分析了伐后崖柏种群径级结构、种群生存力、物种多样性及其群落结构动态等特征。结果表明: 崖柏残 存群落伐后13年崖柏种群个体数量增加了 $22.58 \%$, 其中幼苗幼树占 $85.71 \%$, 而崖柏种群生存率下降 $25.43 \%$, 种群 死亡密度和危险率分别增加了 $24.12 \%$ 和 $28.62 \%$ 。崖柏群落物种丰富度和Shannon-Wiener指数分别增加 $96.43 \%$ 和 $33.35 \%$ 。研究结果表明, 砍伐使崖柏种群生存力及其在群落中的优势度持续下降, 崖柏占优势的针阔混交林有向 阔叶林演替的趋势, 崖柏种群受到严重威胁, 亟需采取紧急保护措施。

关键词: 砍伐; 崖柏; 极小种群野生植物; 种群生存力; 群落结构动态

\section{Community structure and dynamics of a remnant forest dominated by Thuja sutchuenensis after deforestation}

Zhixia Zhao ${ }^{1,2}$, Changming Zhao ${ }^{2}$, Shuyu Deng ${ }^{2,3}$, Guozhen Shen ${ }^{2,3}$, Zongqiang Xie ${ }^{2,3}$, Gaoming Xiong ${ }^{2 *}$, Junqing $\operatorname{Li}^{1 *}$

1 Beijing Key Laboratory for Forest Resources and Ecosystem Processes, Beijing Forestry University, Beijing 100083

2 State Key Laboratory of Vegetation and Environmental Change, Institute of Botany, Chinese Academy of Sciences, Beijing 100093

3 University of Chinese Academy of Sciences, Beijing 100049

\begin{abstract}
As forests are destroyed, remaining habitats may have too little area to sustain viable populations as extinction follows forest loss or fragmentation. Thuja sutchuenensisis, a typical Wild Plant with Extremely Small Populations (WPESP), once been declared extinct in the wild, were rediscovered in 1999. However, recent deforestation is a major threat to $T$. sutchuenensisis survival. Few studies have explored community responses by $T$. sutchuenensisis to long-term logging. Here, we quantified the population size, population viability, and community composition of the remaining T. sutchuenensisis forests following illegal and severe logging, based on three surveyed datasets on the permanent plots in 2004, 2010 and 2016, respectively. The results show that remaining $T$. sutchuenensisis seedlings and saplings had increased by $85.71 \%$ after 13 years of illegal logging. The population survival rate of $T$. sutchuenensisis decreased by $25.43 \%$, in contrast, the death density and extinction risk rate increased by $24.12 \%$ and $28.62 \%$, respectively. Meanwhile the species richness and the Shannon-Wiener index of the community showed an increase with $96.43 \%$ and $33.35 \%$ after 13 years of logging. The results demonstrate that the population viability and the dominance of $T$. sutchuenensisis in the remaining community show strong decline, and the coniferous and broad-leaved mixed forest dominated by T. sutchuenensisis is likely to be replaced by broad-leaved forest. Our results also have important implications for small population conservation, given that the remaining forest may play a unique role in the persistence of $T$. sutchuenensisis.
\end{abstract}

收稿日期: 2019-07-25; 接受日期: 2019-10-08

基金项目: 国家重点研发计划(2016YFC0503100) “极小种群野生植物生存潜力与维持机制研究”课题(2016YFC0503101)和国家科技基础性工作专项 (2015FY1103002)

* 共同通讯作者 Co-authors for correspondence. E-mail: lijq@bjfu.edu.cn; xgm@ibcas.ac.cn 
Key words: deforestation; Thuja sutchuenensis; Wild Plant with Extremely Small Populations (WPESP); population viability; community structure dynamics

森林砍伐导致植物种群个体数量减少, 物种多 样性和群落结构改变(Okuda et al, 2003; 蒋志刚和 马克平, 2014)。研究发现, 砍伐导致热带雨林以 2,101 $\mathrm{km}^{2} /$ 年的速度丧失(Hansen et al, 2013), 预计 到2050年亚马孙森林因砍伐面积将减少 $21 \%-40 \%$, 物种丰富度下降19\%-36\% (Gomes et al, 2019)。砍伐 加剧森林破碎化和退化, 森林生物多样性和生态系 统服务功能急剧下降(Montoya et al, 2010; Rocha et al, 2016)。

极小种群野生植物因其分布地域狭窄、种群衰 减严重, 个体数量低于其稳定存活界限, 随时濒临 灭绝(Ren et al, 2012; 孙卫邦和杨文忠, 2013)。森林 砍伐是引起极小种群野生植物濒危的主要原因之 一(Hansen et al, 2013)。研究发现, 27.5\%的极小种群 野生植物因森林砍伐而濒临灭绝(覃海宁等, 2017)。 物系统发育、古生物和古气候研究具有重要意义, 在全球生物多样性保护中具有特殊的地位和不可 替代的作用(李先琨等, 2002)。崖柏分布范围狭窄、 种群数量少, 灭绝风险极高, 为典型极小种群野生 植物(杨文忠等, 2015)。砍伐是崖柏濒危的主要原因 之一(刘建锋等, 2004)。野生崖柏自发现伊始, 未能 及时得到保护而遭受严重砍伐。部分崖柏分布于农 户承包林中, 农民薪柴和建筑用材砍伐严重(王金金 等, 2016)。同时, 崖柏因其树形美观、木材轻软柔 韧, 具很高的观赏和利用价值, 崖柏根雕疯狂炒卖, 商贩私自收购和盗采严重(刘建锋等, 2004)。目前, 野生崖柏种群主要零星残存于重庆城口县和开县 的悬崖、陡峭山坡或山脊等石灰岩山地(王金等, 2016)。

目前, 对崖柏种群的研究主要集中于种群特征 (Tang et al, 2015)、群落结构(王金等, 2017)、遗传多 样性(Liu et al, 2013)、生理特征(朱莉等, 2014; 刘学 利等, 2015)和生物地理隔离(Peng \& Wang, 2008)等 方面。而关于砍伐后崖柏种群和群落结构将发生何 种变化则鲜有报道。本研究将着重分析重度砍伐后 崖柏种群数量和其群落组成结构等特征, 试图揭示 伐后崖柏种群更新及其群落动态规律, 为崖柏种群

保护和恢复提供科学依据。

\section{材料与方法}

\section{1 研究区概况与样地设置}

研究区位于重庆市开县雪宝山王家岩 (10840'25.8' E, 31³6'54.1" N), 属典型北亚热带湿 润季风气候, 地貌类型为山地, 土壤类型主要为黄 棕壤。崖柏为典型极小种群野生植物, 残存种群数 量极少、分布面积小, 样地设置受到限制。2004年, 我们于重庆市开县雪保山王家岩海拔2,150 m地段 被砍伐的崖柏群落中, 设置 4 个 $10 \mathrm{~m} \times 10 \mathrm{~m}$ 的固定 样地, 样地坡向北偏西 $45^{\circ}$, 坡度为 $43^{\circ}$ 。样地内崖柏 群落属针阔混交林, 乔木层主要有崖柏、铁杉(Tsuga chinensis)、刺叶高山栋(Quercus spinosa)、粉白杜鹃 (Rhododendron hypoglaucum)等; 林下灌木主要有 小叶黄杨(Buxus sinica var. parvifolia)、茵芋(Skimmia reevesiana)等; 草本层主要有薹草(Carex spp.)、 蛇足石杉(Huperzia serrata)等。对样地内乔木层物 种编号挂牌, 胸径 $>2 \mathrm{~cm}$ 的乔木进行每木检尺, 测 定其胸径、树高、枝下高、冠幅以及在样地中的坐 标位置等, 并调查幼苗幼树的更新数量。在每个样 地沿对角线设置 2 个 $5 \mathrm{~m} \times 5 \mathrm{~m}$ 灌木样方, 每个灌木 样方内设置 1 个 $1 \mathrm{~m} \times 1 \mathrm{~m}$ 草本样方, 分种调查灌木 和草本的盖度、平均高度、株数、生长期等。2010 年和2016年分别对固定样地进行了2次复查。

\section{2 崖柏种群径级结构和生存力}

按胸径大小以 $4 \mathrm{~cm}$ 为一级对崖柏径级进行划 分, 共分为I: $0<\mathrm{DBH}<4 \mathrm{~cm}$, II: $4 \leq \mathrm{DBH}<8 \mathrm{~cm}$, III: $8 \leq \mathrm{DBH}<12 \mathrm{~cm}$, IV: $12 \leq \mathrm{DBH}<16 \mathrm{~cm}, \mathrm{~V}: 16 \leq$ $\mathrm{DBH}<20 \mathrm{~cm}$ 和VI: $20 \leq \mathrm{DBH}<24 \mathrm{~cm}$ 等 6 个径级。其 中胸径 $<4 \mathrm{~cm}$ 的个体为幼苗幼树, 胸径 $\geq 4 \mathrm{~cm}$ 的 为成熟个体(王金等, 2016)。

种群生存力计算公式(Silvertown, 1982):

$$
\begin{aligned}
& l_{i}=a_{i} / a_{0} \times 1000 \\
& M_{i}=l_{i+1} / l_{i} \\
& S_{i}=M_{1} \times M_{2} \times M_{3} \times \cdots \times M_{i} \\
& F_{i}=1-S_{i} \\
& f_{t i}=\left(S_{i-1}-S_{i}\right) / h_{i}
\end{aligned}
$$




$$
\lambda_{t i}=2 F_{i} / h_{i}\left(1+S_{i}\right)
$$

其中, $i$ 为径级, $a_{i}$ 为存活个体数, $l_{i}$ 为标准化存活个体 数, $M_{i}$ 为存活率, $h_{i}$ 为径级宽度, $S_{i}$ 为种群生存率, $F_{i}$ 为累积死亡率, $f_{t i}$ 为死亡密度, $\lambda_{t i}$ 为危险率。

\section{3 物种多样性计算}

物种丰富度指数 $=$ 样地内乔木层物种数目 (7)

Shannon-Wiener指数:

$$
H=-\sum_{i=1}^{S} P_{i} \log P_{i}
$$

式中, $S$ 表示出现的物种数, $P_{i}$ 表示第 $\mathrm{i}$ 个物种的多度 比例。

乔木层重要值 $=($ 相对密度 + 相对显著度 + 相对频度) / 3

其中, 相对密度为该种的所有株数比所有种的株数 之和, 相对显著度为该种个体胸高断面积比所有种 的胸高断面积之和，相对频度为该种的频度比所有 种的频度之和。

采用非参数Friedman进行差异显著性检验和多 重比较。数据分析在R 3.5.1中进行。

\section{2 结果}

\section{1 崖柏种群径级结构}

研究发现，伐后13年(2004-2016年)崖柏种群 个体数量增加了 $22.58 \%$ (图1)。崖柏种群个体在I、 II、III和IV径级中数量均显著增加 $(P<0.01)$, 且种 群总个体数均随径级增大而减少, 径级结构呈倒 $\mathrm{J}$ 形，属增长型种群。其中，第 $\mathrm{I}$ 径级个体数量于2004、 2010和2016年分别占崖柏种群数量的 $64.19 \%$ 、

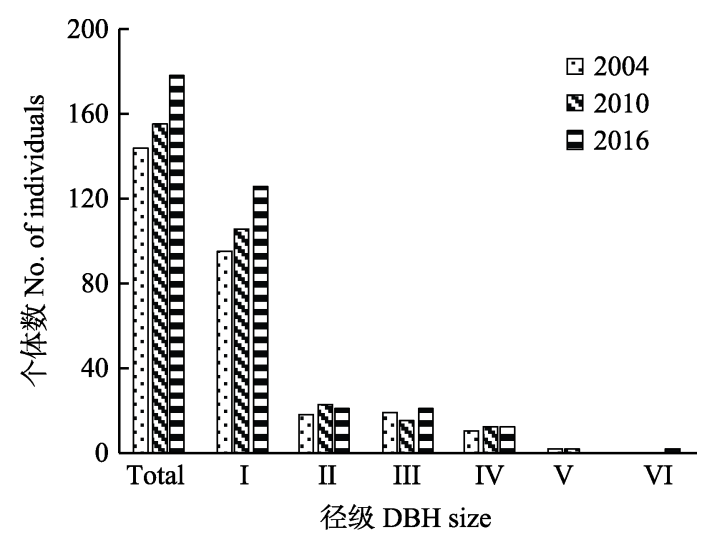

图1 崖柏种群径级结构

Fig. 1 DBH size structure of Thuja sutchuenensis population. I, $0<\mathrm{DBH}<4 \mathrm{~cm}$; II, $4 \leq \mathrm{DBH}<8 \mathrm{~cm}$; III, $8 \leq \mathrm{DBH}<12 \mathrm{~cm}$; IV, $12 \leq \mathrm{DBH}<16 \mathrm{~cm}$; V, $16 \leq \mathrm{DBH}<20 \mathrm{~cm}$; VI, $20 \leq \mathrm{DBH}<$ $24 \mathrm{~cm}$.
67.74\%和70.22\% (图1)。崖柏更新比(幼苗幼树与成 年个体比)增加了 $10.11 \%$, 增加集中于2010-2016年 (图2), 表明崖柏种群更新旺盛。

\section{2 崖柏种群生存力}

研究发现，伐后13年(2004-2016年)崖柏种群 生存率显著下降 $(P<0.01)$, 下降了 $25.43 \%$ (图3)。与 此相反, 崖柏种群累积死亡率、死亡密度和危险率 均极显著上升 $(P<0.01)$ 。其中, 崖柏种群死亡密度 增加了 $24.12 \%$ ，崖柏种群危险率增加了 $28.62 \%$ ，增 加主要集中于2010-2016年间(图3)。崖柏种群累积 死亡率增加了 $2.61 \%$ (图3), 但增加不显著。

\section{3 崖柏群落结构}

研究发现，伐后13年(2004-2016年)崖柏群落 乔木层物种丰富度增加了 $96.43 \%(P<0.05)($ 表1), 增加主要发生于2010-2016年(图4A)。乔木层 Shannon-Wiener指数增加了 $33.35 \%(P<0.05)$ (表1),

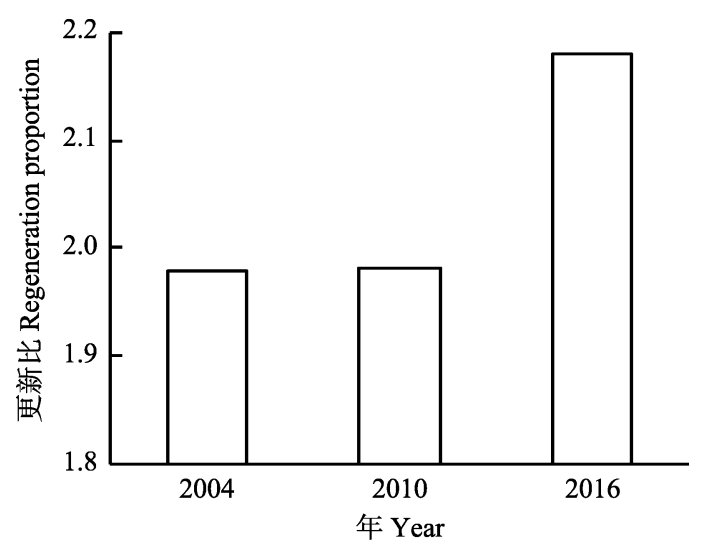

图2 幼苗幼树更新比

Fig. 2 Regeneration proportion of seedlings and saplings

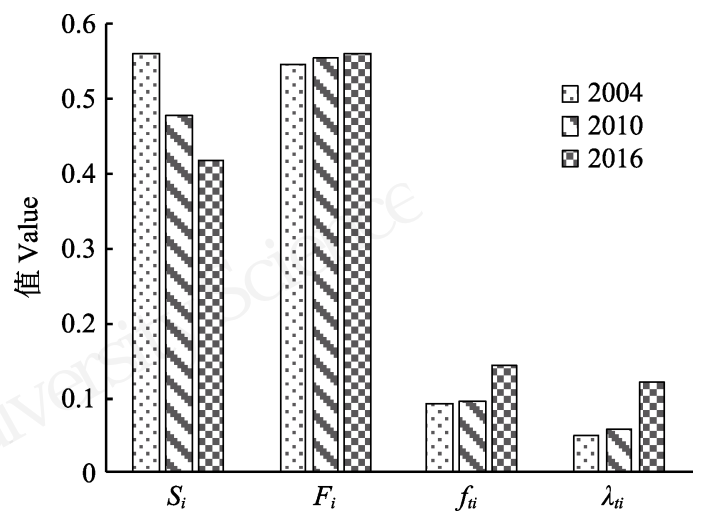

图3 崖柏种群生存力。 $S_{i}$ 为生存率; $F_{i}$ 为累积死亡率; $f_{t i}$ 为死 亡密度; $\lambda_{t i}$ 为危险率。

Fig. 3 Population viability of Thuja sutchuenensis. $S_{i}$ is survival rate; $F_{i}$ is cumulative death rate; $f_{t i}$ is mortality rate density; $\lambda_{t i}$ is hazard rate. 
表1 2004-2016年各变量非参数Friedman方差分析

Table 1 The non-parametric Friedman ANOVA for each variable during 2004-2016. * $P<0.05$.

\begin{tabular}{llllll}
\hline & $\begin{array}{l}\text { 自由度 } \\
\text { Degree of freedom }\end{array}$ & $\begin{array}{l}\text { 平方和 } \\
\text { Sum of squares }\end{array}$ & $\begin{array}{l}\text { Mean square } \\
\text { M方 }\end{array}$ & $F$ & $P$ \\
\hline 物种丰富度 Species richness & 2 & 91.13 & 91.13 & 7.78 & $0.022^{*}$ \\
Shannon-Wiener指数 Shannon-Wiener index & 2 & 0.634 & 0.634 & 6.948 & $0.039^{*}$ \\
崖柏重要值 Importance value of Thuja sutchuenensis & 2 & 336.5 & 336.5 & 4.517 & $0.018^{*}$ \\
针叶树种重要值 Importance value of conifer species & 2 & 500.1 & 500.1 & 4.099 & 0.105 \\
常绿树种重要值 Importance value of evergreen species & 2 & 10.8 & 10.77 & 0.152 & 0.716 \\
\hline
\end{tabular}
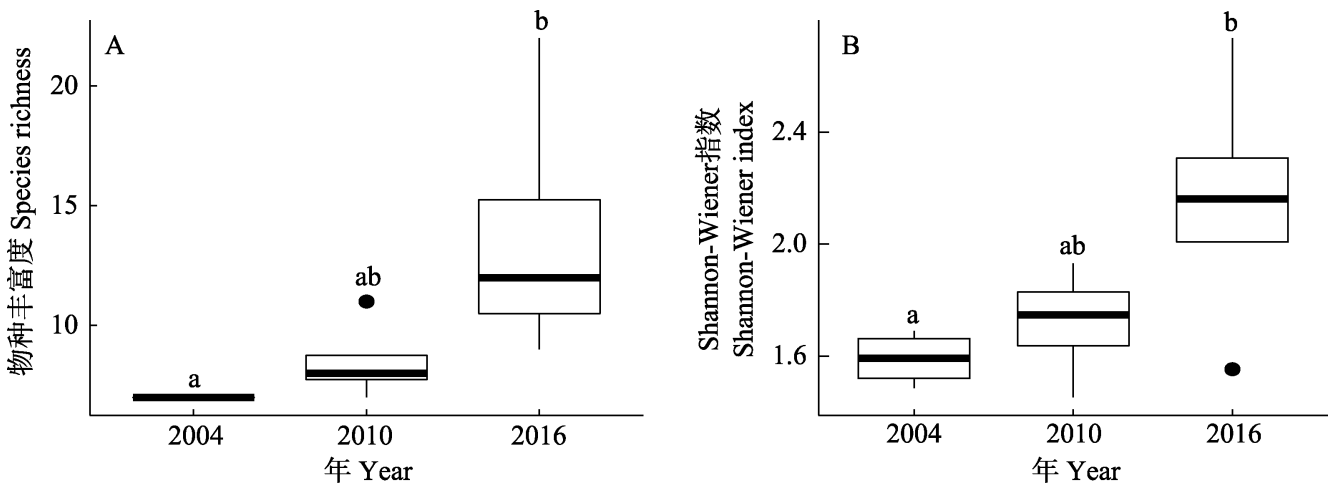

图4 崖柏群落物种丰富度(A)和Shannon-Wiener指数(B)。不同字母表示差异显著 $(P<0.05)$ 。

Fig. 4 Species richness (A) and Shannon-Wiener index (B) of Thuja sutchuenensis community. Different letters indicate significant differences $(P<0.05)$.
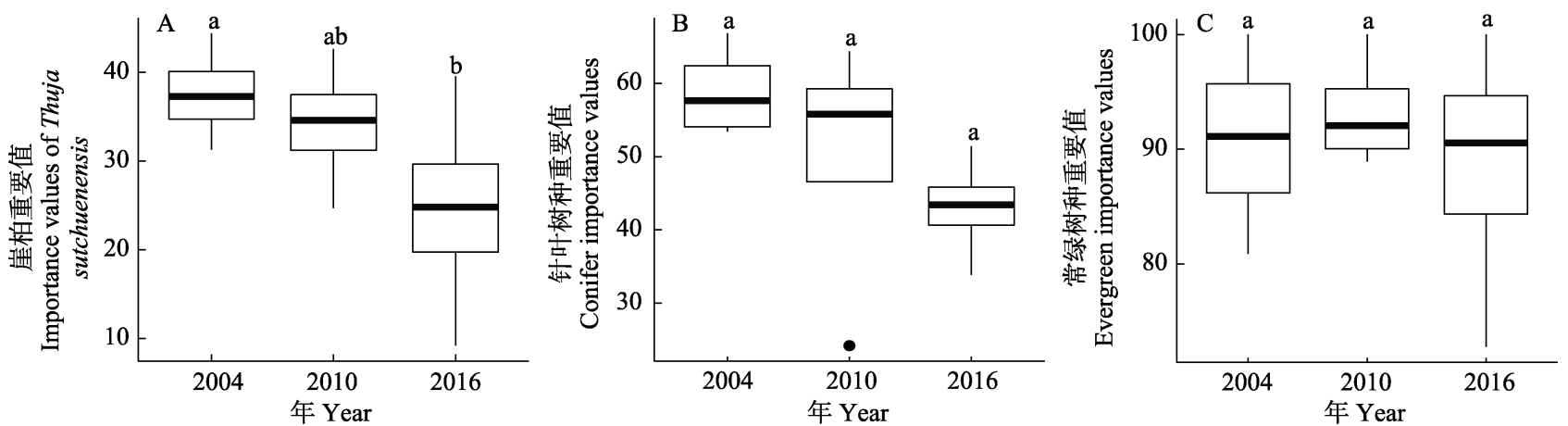

图5 群落中崖柏(A)、针叶树种(B)和常绿树种 $(\mathrm{C})$ 重要值。不同字母表示差异显著 $(P<0.05)$ 。

Fig. 5 The proportion of importance values of Thuja sutchuenensis (A), conifer (B) and evergreen species (C) in the community. Different letters indicate significant differences $(P<0.05)$.

\section{表2 2004-2016年主要乔木物种重要值}

Table 2 Importance value of major tree species in the community during 2004-2016

\begin{tabular}{|c|c|c|c|}
\hline \multirow[t]{2}{*}{ 物种 Species } & \multicolumn{3}{|c|}{ 重要值 Importance value (\%) } \\
\hline & 2004 & 2010 & 2016 \\
\hline 崖柏 Thuja sutchuenensis & 33.74 & 30.99 & 22.09 \\
\hline 铁杉 Tsuga chinensis & 18.03 & 16.89 & 12.73 \\
\hline 刺叶高山栎 Quercus spinosa & 14.22 & 10.18 & 12.30 \\
\hline 粉白杜鹃 Rhododendron hypoglaucum & 11.05 & 13.02 & 15.17 \\
\hline 川陕鹅耳枥 Carpinus fargesiana & 5.39 & 3.52 & 1.88 \\
\hline 吊钟花 Enkianthus quinqueflorus & 4.61 & 3.14 & 1.71 \\
\hline 红柄木犀 Osmanthus armatus & 3.70 & 2.96 & 2.57 \\
\hline 小花八角 Illicium micranthum & 3.68 & 2.50 & 2.16 \\
\hline 云南冬青 Ilex yunnanensis & 3.67 & 1.58 & 1.98 \\
\hline 华西花楸 Sorbus wilsoniana & 1.90 & 1.23 & 1.80 \\
\hline
\end{tabular}

增加主要发生于2010-2016年(图4B)。崖柏的重要值 降低了 $34.53 \%(P<0.05)$, 主要发生于 2010-2016年 间(表1，表2，图5A)。崖柏群落中针叶树种重要值降 低了 26.82\% (图5B); 常绿树种重要值表现为先上 升后下降趋势，其中 2004-2010年上升了 2.72\%, 2010-2016年下降了 5.24\%, 常绿树种重要值下降集 中在2010-2016年间(图5C)。

\section{3 讨论}

径级大小是种群结构的重要特征之一, 种群大 小体现了种群生存能力(Ruprecht et al, 2010)。本研 
究发现, 砍伐后崖柏群落恢复过程中, 其个体数量 持续增加, 表明重度砍伐后崖柏种群更新旺盛, 种 群自我维持能力较强。幼苗阶段植物种群数量变化 大、生长脆弱, 对环境较为敏感(Wright et al, 2005)。 砍伐降低林分密度, 改变林内温度、光照和土壤等 要素(Bataineh et al, 2013)。伐后林内郁闭度下降, 为 幼苗更新提供了充足的光照条件, 有利于幼苗幼树 更新(Rocha et al, 2016; 王金等, 2017)。本研究发现 伐后崖柏个体数量增加主要集中于幼苗幼树阶段。 而胸径 $\geq 4 \mathrm{~cm}$ 的崖柏成熟个体数量比砍伐前减少 了23.19\%，崖柏种群仍未恢复至砍伐前状态。崖柏 胸径增长缓慢 $(0.5-1.1 \mathrm{~mm} / \mathrm{yr})$ 是其成熟个体数量增 加不显著的原因之一(Tang et al, 2015)。砍伐13年后， 崖柏成熟个体平均胸径仅 $9.18 \mathrm{~cm}$, 而2004年第1次 对崖柏群落进行调查时样地内崖柏残存伐桩平均 基径达16.12 cm, 可见重度砍伐使崖柏种群结构遭 到严重破坏，短时间内难以恢复。

种群生存力是种群结构与动态的主要特征之 一, 种群生存率、累积死亡率、死亡密度和危险率 等种群生存力指标反映了种群生存、死亡和危险等 状况(Li \& Zhang, 2015)。本研究发现, 伐后崖柏种 群生存率持续下降, 累积死亡率、死亡密度和危险 率增加, 崖柏种群生存力降低。伐后崖柏种群林分 密度和环境异质性增大, 种内种间资源和空间竞争 加剧, 种群生存力下降(Resende et al, 2016)。同时, 伐后崖柏种群因种群密度制约, 幼苗幼树更新过程 中死亡率极高, 仅有少数幼树进入乔木层(Reynolds \& Ford, 2005), 这可能也是2010-2016年期间崖柏 种群危险率和死亡密度高于2004年的原因之一。另 外, 崖柏幼苗喜荫蔽环境, 砍伐后林下气温和光照 增强, 抑制了幼苗幼树生长, 使崖柏种群生存力降 低(杨文娟等, 2013)。

伐后植物群落恢复过程中, 空间异质性增加, 适宜不同物种定植, 群落生物多样性随之增加(Harmer et al, 2001; Amici et al, 2013; Lennox et al, 2018)。本研究发现, 伐后崖柏群落乔木层物种丰富 度和Shannon-Wiener指数显著增加。乔木层竞争力 强的优势物种对群落结构和内部环境条件起决定 性作用(钟兆全, 2016)。崖柏为乔木层优势种, 具有 较强的环境适应能力和资源竞争优势(Tang et al, 2015)。然而, 由于群落结构和内部环境改变, 许多 阔叶树种如交让木(Daphniphyllum macropodum)、雉
栗(Castanea henryi)、铁木(Ostrya japonica)、香叶子 (Lindera fragrans)、石灰花楸(Sorbus folgneri)等进入 乔木层，加剧了物种间的资源竞争，对崖柏的生长 和恢复产生威胁(Tang et al, 2015)。

重度砍伐改变了森林物种组成, 先锋物种的种 类和数量在森林恢复演替过程中短时间内显著增 加，优势物种被先锋种代替，森林退化并逆向演替 (Berenguer et al, 2014; Magnago et al, 2015)。研究发 现, 崖柏幼树生长缓慢, 远低于群落内刺叶高山栋和 粉白杜鹃等阔叶树种, 伐后崖柏在群落中的重要值 持续降低。未来崖柏可能失去其在乔木层的优势种 地位。崖柏和其他针叶树在群落中的优势地位不断下 降, 群落出现由针阔混交林向阔叶林演替的趋势。

综上, 本研究结果表明, 重度砍伐后崖柏种群 天然更新能力较强, 但种群生存力及其在群落中的 优势地位持续下降，群落表现出由针阔混交林向阔 叶林演替的趋势, 崖柏种群生存受到严重威胁。

\section{参考文献}

Amici V, Santi E, Filibeck G, Diekmann M, Geri F, Landi S, Scoppola A, Chiarucci A (2013) Influence of secondary forest succession on plant diversity patterns in a Mediterranean landscape. Journal of Biogeography, 40, 2335-2347.

Bataineh M, Kenefic L, Weiskittel A, Wagner R, Brissette J (2013) Influence of partial harvesting and site factors on the abundance and composition of natural regeneration in the Acadian forest of Maine, USA. Forest Ecology and Management, 306, 96-106.

Berenguer E, Ferreira J, Gardner TA, Aragao LEOC, Decamargo PB, Cerri CE, Durigan M, Deoliveira RC, Vieira ICG, Barlow J (2014) A large-scale field assessment of carbon stocks in human-modified tropical forests. Global Change Biology, 20, 3713-3726.

Gomes VHF, Vieira ICG, Salomao RP, Steege H (2019) Amazonian tree species threatened by deforestation and climate change. Nature Climate Change, 9, 547-553.

Hansen MC, Potapov PV, Moore R, Hancher M, Turubanova SA, Tyukavina A, Thau D, Stehman SV, Goetz SJ, Loveland TR, Kommareddy A, Egorov A, Chini L, Justice CO, Townshend JRG (2013) High-resolution global maps of 21st-century forest cover change. Science, 342, 850-853.

Harmer R, Peterken G, Kerr G, Poulton P (2001) Vegetation changes during 100 years of development of two secondary woodlands on abandoned arable land. Biological Conservation, 101, 291-304.

Jiang ZG, Ma KP (2014) The Principle of Conservation Biology. Science Press, Beijing. (in Chinese) [蒋志刚, 马克 平 (2014) 保护生物学原理. 科学出版社, 北京.] 
Lennox GD, Gardner TA, Thomson JR, Ferreira J, Berenguer E, Lees AC, Mac NR, Aragao LEOC, Ferraz SFB, Louzada J, Moura NG, Oliveira VHF, Pardini R, Solar RRC, Mello FZV, Vieira ICG, Barlow J (2018) Second rate or a second chance? Assessing biomass and biodiversity recovery in regenerating Amazonian forests. Global Change Biology, 24, 5680-5694.

Li W, Zhang GF (2015) Population structure and spatial pattern of the endemic and endangered subtropical tree Parrotia subaequalis (Hamamelidaceae). Flora, 212, 10-18.

Li XK, Su ZM, Xiang WS, Ning SJ, Tang RQ, Ou ZL, Li RT (2002) Study on the structure and spatial pattern of the endangered plant population of Abies yuanbaoshanensis. Acta Ecologica Sinica, 22, 2246-2253. (in Chinese with English abstract) [李先琨, 苏宗明, 向悟生, 宁世江, 唐润 琴, 欧祖兰, 李瑞棠 (2002) 濒危植物元宝山冷杉种群结 构与分布格局. 生态学报, 22, 2246-2253.]

Liu JF, Shi SQ, Chang EM, Yang WJ, Jiang ZP (2013) Genetic diversity of the critically endangered Thuja sutchuenensis revealed by ISSR markers and the implications for conservation. International Journal of Molecular Sciences, 14, 14860-14871.

Liu JF, Xiao WF, Guo ZH, Jiang ZP, Liu ZY (2004) A preliminary study on population structure and dynamics of a rare and endangered plant, Thuja sutchuenensis (Cupressaceae). Acta Agriculturae Universitatis Jiangxiensis, 26, 377-380. (in Chinese with English abstract) [刘建锋, 肖文发, 郭志 华, 江泽平, 刘正宇 (2004) 珍稀濒危植物一一崖柏种群 结构与动态初步研究. 江西农业大学学报, 26, 377-380.]

Liu XL, Guo X, Zhang ZX, Zhang SQ, Wang D (2015) Morphological observation on strobilus and seed cones of an endangered plant, Thuja sutchuenensis Franch. Journal of Central China Normal University (Natural Sciences), 49, 424-427. (in Chinese with English abstract) [刘学利, 郭璇, 张中信, 张世强, 王东 (2015) 崖柏球花和球果形态特征 的补充描述. 华中师范大学学报 (自然科学版), 49, 424-427.]

Magnago LFS, Magrach A, Laurance WF, Martins SV, Meira NJAA, Simonelli M, Edwards DP (2015) Would protecting tropical forest fragments provide carbon and biodiversity cobenefits under REDD plus? Global Change Biology, 21, 3455-3468.

Montoya D, Alburquerque FS, Rueda M, Rodriguez MA (2010) Species' response patterns to habitat fragmentation: Do trees support the extinction threshold hypothesis? Oikos, 119, 1335-1343.

Okuda T, Suzuki M, Adachi N, Quah ES, Hussein NA, Manokaran N (2003) Effect of selective logging on canopy and stand structure and tree species composition in a lowland dipterocarp forest in Peninsular Malaysia. Forest Ecology and Management, 175, 297-320.

Peng D, Wang XQ (2008) Reticulate evolution in Thuja inferred from multiple gene sequences: Implications for the study of biogeographical disjunction between Eastern Asia and North America. Molecular Phylogenetics and Evolution, 47, 1190-1202.

Qin HN, Zhao LN, Yu SX, Liu HY, Liu B, Xia NH, Peng H, Li ZY, Zhang ZX, He XJ, Yin LK, Lin YL, Liu QR, Hou YT, Liu Y, Liu QX, Cao W, Li JQ, Chen SL, Jin XH, Gao TG, Chen WL, Ma HY, Geng YY, Jin XF, Chang CY, Jiang H, Cai L, Zang CX, Wu JY, Ye JF, Lai YJ, Liu B, Lin QW, Xue NX (2017) Evaluating the endangerment status of China's angiosperms through the red list assessment. Biodiversity Science, 25, 745-757. (in Chinese with English abstract) [覃海宁, 赵莉娜, 于胜祥, 刘慧圆, 刘博, 夏念 和, 彭华, 李振宇, 张志翔, 何兴金, 尹林克, 林余霖, 刘 全儒, 侯元同, 刘演, 刘启新, 曹伟, 李建强, 陈世龙, 金 效华, 高天刚, 陈文俐, 马海英, 耿玉英, 金孝锋, 常朝 阳, 蒋宏, 蔡蕾, 藏春金金, 武建勇, 叶建飞, 赖阳均, 刘 冰，林秦文，薛纳新 (2017) 中国被子植物濒危等级的评 估. 生物多样性, 25, 745-757.]

Ren H, Zhang QM, Lu HF, Liu HX, Guo QF, Wang J, Jian SG, Bao HO (2012) Wild plant species with extremely small populations require conservation and reintroduction in China. Ambio, 41, 913-917.

Resende RT, Marcatti GE, Pinto DS, Takahashi EK, Cruz CD, Resende MDV (2016) Intra-genotypic competition of Eucalyptus clones generated by environmental heterogeneity can optimize productivity in forest stands. Forest Ecology and Management, 380, 50-58.

Reynolds JH, Ford ED (2005) Improving competition representation in theoretical models of self-thinning: A critical review. Journal of Ecology, 93, 362-372.

Rocha SL, Pessoa MS, Cassano CR, Talora DC, Orihuela RLL, Mariano NE, Morante JC, Faria D, Cazetta E (2016) The shrinkage of a forest: Landscape-scale deforestation leading to overall changes in local forest structure. Biological Conservation, 196, 1-9.

Ruprecht E, Enyedi MZ, Eckstein RL, Donath TW (2010) Restorative removal of plant litter and vegetation 40 years after abandonment enhances re-emergence of steppe grassland vegetation. Biological Conservation, 143, 449-456.

Silvertown JW (1982) Introduction to Plant Population Ecology. Longman Group United Kingdom, London.

Sun WB, Yang WZ (2013) Conserving Plant Species with Extremely Small Populations (PSESP) in Yunnan. Yunnan Science and Technology Press, Kunming. (in Chinese) [孙 卫邦, 杨文忠 (2013) 云南省极小种群野生植物保护实 践与探索. 云南科技出版社, 昆明.]

Tang CQ, Yang YC, Ohsawa M, Momohara A, Yi SR, Robertson K, Song K, Zhang SQ, He LY (2015) Community structure and survival of Tertiary relict Thuja sutchuenensis (Cupressaceae) in the subtropical Daba Mountains, Southwestern China. PLoS ONE, 10, e0125307.

Wang X, Liu Q, Huang Q, Zhang HY, Li ZF, Zhang SQ, Deng HP (2017) Niche characteristics and CCA ordination of 
dominant species of Thuja sutchuenensis community. Journal of Beijing Forestry University, 39(8), 60-67. (in Chinese with English abstract) [王金金, 刘钦, 黄琴, 张华雨, 李宗 峰, 张世强, 邓洪平 (2017) 崖柏群落优势种生态位及 CCA排序分析. 北京林业大学学报, 39(8), 60-67.]

Wang X, Zhang HY, Li ZF, Zhang SQ, Wang GX, Deng HP (2016) Community structure and population regeneration of an endangered plant, Thuja sutchuenensis. Journal of Beijing Forestry University, 38(10), 28-37. (in Chinese with English abstract) [王金金, 张华雨, 李宗峰, 张世强, 王国 行, 邓洪平 (2016) 濒危植物崖柏群落特征及种群更新 研究. 北京林业大学学报, 38(10), 28-37.]

Wright SJ, Muller LHC, Calderon O, Hernandez A (2005) Annual and spatial variation in seedfall and seedling recruitment in a neotropical forest. Ecology, 86, 848-860.

Yang WJ, Jiang ZP, Liu JF, Guo QS (2013) Diurnal photosynthetic dynamic of Thuja sutchuenensis under different light environments. Forest Research, 26, 373-378. (in Chinese with English abstract) [杨文娟, 江泽平, 刘建锋, 郭泉 水 (2013) 不同光环境下濒危植物崖柏的光合日动态. 林业科学研究, 26, 373-378.]

Yang WZ, Xiang ZY, Zhang SS, Kang HM, Shi FQ (2015)
Plant species with extremely small populations (PSESP) and their significance in China's national plant conservation strategy. Biodiversity Science, 23, 419-425. (in Chinese with English abstract) [杨文忠, 向振勇, 张珊珊, 康洪梅, 史富强 (2015) 极小种群野生植物的概念及其对我国野 生植物保护的影响. 生物多样性, 23, 419-425.]

Zhong ZQ (2016) Analysis of community competition for tree layer of Castanopsis carlesii natural secondary forests in northern Fujian. Journal of Beihua University (Natural Science), 17, 674-678. (in Chinese with English abstract) [钟兆 全 (2016) 闽北米槠天然次生林乔木层群落竞争关系分 析. 北华大学学报(自然科学版), 17, 674-678.]

Zhu L, Guo QS, Zhu NN, Qin AL, Xu GX, Xing JC (2014) Study on the cones and seeds biological characteristic of a critically endangered species, Thuja sutchuenensis, in the world. Seed, 33, 56-59. (in Chinese with English abstract) [朱莉, 郭泉水, 朱妮妮, 秦爱丽, 许格希, 邢继畴 (2014) 世界级极危物种——崖柏的球果和种子性状研究. 种子, 33, 56-59.]

(责任编委: 张大勇 责任编辑: 黄祥忠) 